\title{
AVALIAÇÃO E RESPONSABILIZAÇÃO: USOS E APROPRIAÇÕES NO SISTEMA MUNICIPAL DE ENSINO DE MOSSORÓ-RN (2010-2015)
}

\author{
Allan Solano Souza ${ }^{1}$ \\ Ciclene Alves da Silva ${ }^{2}$
}

Resumo: A política de responsabilidade educacional (PRE) de Mossoró-RN incorporou pressupostos da nova gestão pública, tendo como pilares a prestação de contas, avaliação e responsabilização. Analisam-se usos e apropriações destes dois últimos. Realizaram-se a construção do referencial teórico, uma análise documental, combinados com uma entrevista semiestruturada com um representante da sociedade civil. Os resultados revelam que a avaliação é utilizada em processos de premiações material e simbólica, dados que fortalece a responsabilização pela competição administrada e pelo controle de resultados. Conclui-se que esta competição obstrui a livre iniciativa das escolas na concepção de suas próprias políticas, com tarefas burocráticas.

Palavras-chave: Avaliação. Responsabilização. Sistema Municipal de Ensino.

\section{EVALUATION AND RESPONSIBILISATION: USES AND APPROPRIATIONS IN THE EDUCATION SYSTEM OF MOSSORÓ-RN (2010-2015)}

\begin{abstract}
The policy of educational responsibility of Mossoró-RN has incorporated presuppositions of a new public management, based on accountability. Uses and appropriations of the latter two are analyzed. Was carried out the survey of the theoretical reference, document analysis, combined with a semi structured interview with a representative of civil society. The results reveal that evaluation is used for processes of material and symbolic awards, what strengthens the responsibility through managing competition and control of results. Thus, one has concluded that competition obstructs the free initiative of schools in the creation of their own policies with bureaucratic tasks.
\end{abstract}

Keywords: Evaluation, Responsibilisation, Municipal Educational System.

\footnotetext{
${ }^{1}$ Professor Adjunto IV, da Universidade Estadual do Rio Grande do Norte - UERN, onde é docente na Faculdade de Educação e no Programa de Pós-Graduação em Educação. Líder do Grupo de Estudos e Pesquisas em Estado, Educação e Sociedade. E-mail: asolanosouza@ gmail.com

${ }^{2}$ Professora Adjunta IV, do Departamento de Educação da UERN. Realiza estudos e pesquisas sobre políticas e gestão da educação. E-mail:ciclenealves@ bol.com.br
} 


\section{INTRODUÇÃO}

As políticas de avaliação e responsabilização têm sido incorporadas cada vez mais nos sistemas educacionais, forçando mudanças que refletem diretamente na (re)organização das escolas. É a partir da década de 1990, que os estudos sobre avaliação da educação básica no Brasil são revigorados, seguindo nos idos dos anos 2000 inaugurando uma nova fase de reflexões, apropriação e usos das políticas de avaliação alinhadas com as práticas de responsabilização. Sendo assim, nas duas últimas décadas, o foco dos estudos sobre avaliação da educação se desloca "da avaliação externa da educação básica para a avaliação da educação como mecanismo de gestão educacional por resultados" (PASSONE, 2014, p.426), com preponderantes discussões que revelam novas faces da gestão educacional, a "responsabilização da escola", de seus profissionais e dos resultados produzidos pelos sistemas de ensino.

No Brasil, governos estaduais e municipais têm incentivado esta prática na educação, principalmente por meio da propagação de incentivos financeiros como forma de premiação e reconhecimento pelos desempenhos das escolas. A principal punição aplicada pelos governos as instituições que não conseguem alcançar resultados satisfatórios, principalmente os que utilizam como referência a melhoria do Índice de Desenvolvimento da Educação Básica, tem sido deixar do lado de fora das premiações.

Com essas novas possibilidades, estados e municípios, diante da autonomia relativa outorgada pela CF de 1988, para criarem seus sistemas de ensino, e elaborarem as suas políticas e definirem na forma da lei os seus sistemas de ensino foram ao longo das últimas décadas delineando as suas mais diversas formas de organização de sistemas educacionais, principalmente naqueles municípios em que optaram pela construção de sistemas próprios, mas articulados com os sistemas estaduais e com as políticas nacionais.

Estas reflexões estão potencialmente articuladas com um contexto mais amplo de mudanças nas relações entre Estado e Sociedade, assim como em decorrência da redefinição do Papel do Estado, e as respostas encontradas para a crise do seu modelo burocrático, que se 
configurou a partir de um novo modelo de gestão. Além disso, não se descarta a possibilidade dos efeitos dos processos de globalização em seus diferentes níveis.

O contexto que marca essas mudanças é decorrente dos processos de globalização política, econômica e social, e seus fundamentos são encontrados no contexto da crise do modelo burocrático, que se orientou nos princípios da New Public Manangement (HOOD, 1995; GRUENING, 2001) imersos no pensamento neoliberal que exerceu forte influência nos processos de decisão política. Esta concepção atribui ao indivíduo ou as instituições a responsabilidade individual e coletiva (ARENDT, 2004), pelos sucessos e fracassos dos resultados alcançados em sua trajetória pessoal (HARVEY, 2011a, 2011b). Nesse contexto, a gestão educacional por resultados foi a estratégia encontrada pelos reformadores empresariais da educação (FREITAS, 2012) para inserir os princípios da nova gestão pública na educação tais como: eficiência, eficácia e a efetividade em direção a meritocracia.

Considerando esses elementos introdutórios, este artigo foi organizado em três seções, em que na primeira realiza uma abordagem sobre a avaliação no contexto das atuais políticas educacionais. Na segunda seção, discutem-se alguns elementos dos processos de responsabilização. E na terceira seção há uma análise acerca da avaliação e da responsabilização como componentes da política de responsabilidade educacional de Mossoró-RN. Diante deste percurso, este texto apresenta ao final algumas conclusões.

\section{A AVALIAÇÃO NO CONTEXTO DAS ATUAIS POLÍTICAS EDUCACIONAIS}

A avaliação da Educação brasileira conquista espaço marcante a partir da década de 1990 com a assunção do Estado Avaliador, conforme propõe Schneider e Rostirola (2015). O Estado Avaliador pode ser explicado pelo contexto das atuais políticas em educação, delineadas pela busca excessiva por resultados, em que estas são fortemente influenciadas pela implantação de políticas mercadológicas, corroborando para incorporar o projeto ideológico de uma educação de "quase-mercado"”, segundo palavras das autoras.

\footnotetext{
${ }^{3}$ São quase mercados porque difere da natureza dos mercados convencionais em aspectos importantes. Um dos aspectos pode ser exemplificado pelo fato da educação pública não visar a maximização dos seus lucros, em termos financeiros.
} 
No Brasil, o Estado-Avaliador tem adotado políticas de acompanhamento do desempenho das escolas, objetivando a orientação na construção de políticas públicas (FREITAS, 2011). A avaliação é utilizada e sentida como estratégia de governação em que o Estado atua mediante os resultados obtidos em testes organizados e realizados pelo país, podendo, por conseguinte, serem incorporados pelos sistemas estaduais e municipais de educação. Este cenário tem contribuído significativamente para a elaboração de sofisticados mecanismos de controle e responsabilização pelos resultados educacionais por parte das unidades de ensino.

A questão a ser debatida é saber se a avaliação no cenário descrito tem contribuído para diminuir as severas e profundas desigualdades sociais, principalmente por propor no seu interior, dentre outras coisas, à homogeneização dos projetos educativos, bem como a competitividade e a seletividade no âmbito da escola pública brasileira. Pois, conforme a Constituição de 1988 é direito e dever do Estado oferecer uma educação, pública, gratuita e de qualidade. Assim, toda e qualquer reforma educacional deverá buscar amenizar as inferioridades do sistema educativo, melhorando a qualidade dos processos, garantido que os sujeitos a quem o ato educacional se destina tenham reais condições de se viabilizarem na sociedade através da educação que lhe foi ofertada.

Ravitch (2011) ${ }^{4}$ argumenta sobre os "riscos" da educação nacional norteamericana na medida em que foi direcionada aos moldes das práticas da gestão mercadológica, em que os resultados são os fins últimos da educação e não os meios para se atingir o sucesso escolar. As afirmações da autora na obra "Vida e Morte do Grande Sistema Escolar Americano: como os testes padronizados e o modelo de mercado ameaçam a educação”, são frutos de sua vivência na gestão de políticas públicas do Estado Americano na década de 1990 na área da educação. É nesse enredo que no Brasil as políticas de avaliação têm se constituído como eixo estruturante das reformas da administração escolar.

Considerando a esfera mais ampla, tem-se a globalização deste atual modelo de governança do público, a exemplo da OCDE - Organização para Cooperação e Desenvolvimento Econômico, que assumiu o protagonismo internacional das avaliações em

\footnotetext{
${ }^{4}$ A autora propõe uma reflexão sobre o sistema escolar americano a partir de sua experiência na gestão educacional do país, momento este que desenvolveu uma política educacional direcionada por resultados, aos moldes do que ocorre na orientação da política educacional brasileira.
} 
larga escala, construindo uma consensualidade relativa para legitimar a eficácia das avaliações por resultados como mecanismo balizador para o planejamento das políticas locais. Os países signatários desse modelo de avaliação têm orientado seu ensino a partir de uma multiplicidade de testes que são aplicados nacionalmente e regionalmente, o que evidencia a imersão dessas localidades numa prática de regulação mercantil, que na visão de alguns autores, a exemplo de Freitas (2011), não é resultado simplesmente da nova conjuntura política, mas efetivamente de um contexto internacional favorável a regulação social em todas as esferas do social.

O desdobramento de um sistema nacional de avaliação no Brasil se proliferou nos anos de 1990, pois foi a partir deste período que se iniciava uma nova fase na gestão dos serviços públicos no Brasil, voltada ao controle das instituições, redução de custos e aumento da eficiência dos serviços prestados (gerencialismo). O debate acadêmico sobre uma boa educação, portanto, uma educação de qualidade, foi atravessado pela tentativa de formação de um sistema nacional de avaliação com fins para a accountability, adentrando formalmente na Legislação Educacional e no Plano Nacional de Educação-PNE (2001-2010) (BRASIL, 2001) sob o apelo da descentralização administrativa e autonomia das escolas.

Portanto, com a implementação do Sistema Avaliação da Educação Básica - SAEB, atendendo a demanda de políticas globais, perseguindo orientações de Organismos Internacionais, como o Banco Mundial e a OCDE, a avaliação censitária com dados sobre a situação educacional das escolas e redes de ensino tornaram-se uma ação sistemática no país, tornando-se instrumento para o fortalecimento e aprimoramento das políticas educacionais aos moldes praticados pelos países mais avançados da OCDE. Saliente-se que alguns Estados e municípios brasileiros implantaram Programas de Avaliação e Desempenho da Rede Pública Escolar ${ }^{5}$. Para este estudo foi selecionado o município de Mossoró-RN que se aventurou na construção de um sistema próprio de avaliação da educação. Do ponto de vista do crescimento de municípios com esta realidade, observa-se que

O maior crescimento em termos de número de municípios que constituíram sistemas próprios de avaliação deu-se entre os anos de 2005 e 2013. Nesse período, houve 1.257 novas iniciativas. Apesar de muitos recorrerem a assessorias externas para elaboração de suas propostas, seja por meio de consultorias independentes, empresas especializadas ou universidades, sabe-se que o Saeb é a fonte inspiradora da maioria delas tanto no âmbito

\footnotetext{
${ }^{5}$ Tem-se como exemplo o Estado de Pernambuco; Minas Gerais; Ceará e São Paulo.
} 
dos estados da federação como dos municípios (SCHINEIDER; ROSTIROLA, p. 501, 2015).

Embora o Brasil tenha implementado o seu sistema nacional de avaliação nos idos de 1990, a natureza de sua implementação difere do momento atual, pois a concepção dos indicadores sintéticos tem protagonizado novos rumos na educação brasileira, aproximando-se mais de um conceito de responsabilização pelo controle dos resultados atribuída a alguns sujeitos (escola e sociedade por exemplo. O Índice de Desenvolvimento da Educação Básica IDEB é um destes indicadores que tem sido utilizado como meio para promover processos de "responsabilização" pelo controle de resultados, para o balizamento do que seria a oferta de um bom ou mal ensino para os órgãos da autarquia da administração federal.

Assim, o IDEB inserido no sistema nacional da educação brasileira em 2007, que combina dados de rendimento escolar, obtidos mediante resultados da Prova Brasil, juntamente com as taxas de aprovação de uma determinada série a cada dois anos, constituindo-se como o expoente máximo da educação brasileira em exemplo de accountability, a observância da meta 7 (sete) do PNE, onde este indicador é declarado a condição de uma política de Estado. Por aqui, estar-se a perceber que o Brasil declarou oficialmente sua condição de Estado Avaliador e protagonista de uma educação de "quase-mercado" da coisa pública. Resta saber até qe ponto esta condição do ensino brasileiro favorecerá a melhoria da qualidade da educação ofertada nos mais de cinco mil municípios da federação

Graças à sua fórmula de composição, o IDEB alçou a Prova Brasil ao status de avaliação
majoritária na aferição e monitoramento do desempenho escolar de estudantes de
Educação Básica. A atribuição das metas por escola, projetadas a partir das aferições
bianuais da Prova Brasil, evidencia o esforço compreendido pelo país na implantaçâo de
políticas educacionais com finalidades de accountability permitindo conformar o
primeiro estágio do Estado-avaliador. Com as mudaç̧as operados no sistema de
avaliação a partir de 2005, o papel do Estado passou a ser o de regulação e controle,
associado, contraditoriamente, ao discurso da descentralização, democratização da
gestão pública e autonomia das escolas e dos sistemas educativos (SCHINEIDER;
ROSTIROLA, p. 502, 2015).

Esta assertiva permite esclarecer que a construção de política educacional através de resultados, e no caso do Brasil, considerando o indicador do IDEB, tem-se como parâmetros dados estatísticos orientando a elaboração de políticas públicas que deveriam visar o combate a gritante desigualdade social em que opera o sistema público escolar brasileiro. Portanto, cabe 
fazer o seguinte questionamento: é possível uma política educacional ser "pensada" e "gestada" considerando como ponto fulcral dados censitários/estatísticos?

Sem dúvida, o indicador do IDEB é uma variável importantíssima para condução da educação pública brasileira, no entanto, ele sozinho não consegue abarcar a complexidade das demais variáveis inerentes ao processo educacional, a saber: condições físicas da escola, gestão escolar, proposta didático e pedagógica, condições de trabalho dos profissionais da educação, ambiente educativo, etc... A proposta de se planejar e construir um sistema educacional consolidado ultrapassa e muito os processos de accountability em curso no país, ou seja, de uma gestão das políticas públicas focadas em resultados. Um sistema nacional de avaliação forte e preciso deve ser seus processos (o pedagógico) e insumos (investimentos) adequados a necessidade de cada Região, Estado e Município.

Por esta lógica, evidencia-se uma proposta de educação nacional, através de suas políticas de avaliação, vinculada ao modelo de administração pública do Estado Avaliador, centrando esforços no controle dos escores obtidos pelo sistema de avaliação e assentado na vontade de maximização dos lucros/resultados, expandindo e intensificando políticas de mercadorização da educação no contexto que muito extrapola a esfera nacional. Estas iniciativas vêm sendo desenvolvidas e aperfeiçoadas pelo Instituto Nacional de Estudos e Pesquisas Educacionais (INEP), que desde 1997, passou a ter a incumbência de planejar, orientar e coordenar o desenvolvimento de sistemas e projetos de avaliação educacional, objetivando o estabelecimento de indicadores de desempenho das atividades de ensino no país.

\section{RESPONSABILIZAÇÃO E POLÍTICAS EDUCACIONAIS NO BRASIL}

A ideia de introduzir formas de responsabilização nas políticas educacionais se torna mais presente a partir das Conferências Estaduais e Municipais de Educação, realizadas a partir da segunda metade dos anos 2000, com intuito de inserir melhorias nos processos de controle e de resultados escolares e dos sistemas de ensino. Todavia, o sentido do conceito "responsabilização" neste cenário tem se configurado em uma perspectiva de determinar consequências para os maus resultados apresentes pelas organizações públicas, com recorte para as escolas e os sistemas de ensino, por um lado. Por outro lado, há um limite teórico nas 
referências da educação que emperram o avanço do debate acadêmico quando o assunto é a combinação entre avaliação e responsabilização. Logo, é muito difícil conceber um sistema de accountability sem prescindir da avaliação, e que a responsabilização sem avaliação é uma situação problemática. Por isso, a partir de então centraremos esforços para tornar as formas de responsabilização mais compreensíveis e delineadas de forma crítica.

O conceito de responsabilização por muitas vezes é confundido com "responsabilidade", no sentido de "chamar para responder". No campo da gestão pública, o conceito de responsabilização se tornou mais presente, basilado nas orientações do referencial gerencialista para atribuir consequências pelos resultados obtidos. Outrossim, é um conceito que tem sido comumente traduzido do termo inglês accountability, incorporado do modelo empresarial, que tem como ideal atribuir o fracasso nos resultados das organizações aos indivíduos, em que do ponto de vista do mercado, os homens devem ser chamados a responder individualmente pelos resultados. Além disso, possui respaldo nesta matriz ideológica, transferindo atividades do Estado que exigem menor poder de decisão, para aqueles que estão em ação no cotidiano organizacional e que foram possivelmente submetidos a um processo de "parceria públicoprivada", típica das atividades não-estatais e de agentes do setor privado.

Bresser-Pereira (2006) afirma que as formas clássicas e gerenciais de responsabilização ${ }^{6}$ consistem em frutos de processos de reformas, a exemplo, da reforma na gestão pública que ocorreu no Brasil a partir de 1995. A origem das formas de responsabilização revela que foram adotadas com a prerrogativa de impedir o abuso de poder e a corrupção. Corroborando com esta afirmativa, Anastasia (2006) explica que as formas de responsabilização sofrem variações, tais como: formas clássicas (controle parlamentar) ${ }^{7}$ e contemporâneas (responsabilização pelo controle de resultados; controle social e; competição administrada).

A responsabilização pelo controle de resultados acontece mediante a criação e controle de indicadores que vislumbram o alcance de metas planejadas e controladas pelo Poder

\footnotetext{
${ }^{6}$ A obra "Responsabilização na Administração Pública" coordenada por Bresser-Pereira e Grau (2006), em nome do Conselho Científico do CLAD discute sistematicamente as "formas clássicas e gerenciais de responsabilização na administração da do aparelho de Estado" (BRESSER-PEREIRA, 2006, p. 7), ressaltando que a reforma da gestão pública de 1995 continua avançando no Brasil, nos estados e municípios. Por se tratar de uma reforma de grande porte, Bresser-Pereira afirma que durará anos.

${ }^{7}$ Segundo Anastasia (2006, p. 78), “os controles clássicos no Estado constitucional têm por objeto a limitação e o controle do poder" por meio da divisão dos poderes, nos sistema de controles e contrapesos. Estes podem ser classificados em três tipos de controles: administrativo, parlamentar e judicial.
} 
Executivo. O exagero na definição de muitos indicadores é um problema sério na administração pública, principalmente quando chega ao ponto em que nem os planejadores têm clareza quanto ao uso e a função destes. Geralmente, esta forma de responsabilização é precedida ou complementada por processos de avaliação e prestação de contas. Quando este processo é finalizado, apela-se a meritocracia como forma de premiar aqueles que conseguiram avançar nos resultados, ou que não retrocederam de um ano para o outro (QUIRÓS, 2006).

Já a responsabilização pela competição administrada é comum nos ambientes em que se preocupam com a criação de rankings e definição de um organograma rígido. São duas as formas de competição nesse sentido: a competição entre os órgãos da administração pública e a concorrência entre os diferentes provedores de serviços públicos, como por exemplo, as instituições do terceiro setor. Neste tipo de responsabilização "o Estado continua como o grande financiador e responsável último", e repassa a execução de serviços públicos a entes nãoestatais ou agentes privados (ABRUCIO, 2006, p. 222).

Deste modo, uma forma híbrida de responsabilização objetiva introduzir mecanismos competitivos, que em nossa avaliação se reconfigura em um projeto ideológico que tem como papel transmitir a ideia de que as oportunidades de competição são para todos, e cabe aos melhores ocuparem os primeiros lugares. Ora, a introdução de mecanismos de competição na educação ${ }^{8}$ pode significar um grande risco que converge para a privatização das atividades estatais, na medida em que esta forma de responsabilização incorporada nos sistemas de ensino e nas escolas, não considera a natureza do trabalho pedagógico, e considerando a estrutura das escolas nem todas dispõem das mesmas condições materiais e de recursos humanos para competir. Inclusive, estudos acadêmicos revelam que não é interesse do poder público, quando orientado por esta concepção, proporcionar as mesmas condições de existência. No "paraíso da competição" 9 " apregoado pelos empresários da educação, prevalece a lógica de "fazer mais e melhor com menos recursos".

Finalmente, a última forma de responsabilização, que está associada ao controle social. Geralmente, esta forma recorre a setores da sociedade responsáveis pela fiscalização e

\footnotetext{
${ }^{8}$ Ao considerar um país como o nosso de dimensões continentais, são perceptíveis as diferenças e as dificuldades de alcance das políticas socais às comunidades mais distantes dos grandes centros. Isto não quer dizer que não há "problemas no paraíso" dos grandes centros.

${ }^{9}$ A expressão "paraíso da competição" é utilizada nesse texto parafraseando a leitura da obra "Problemas no Paraíso: o comunismo depois do fim da história" do filósofo Slavoj Zizek (2015).
} 


\section{REVISTA DE ADMINISTRAÇÃO EDUCACIONAL}

acompanhamento de políticas públicas, através de instituições como o Ministério Público, Conselhos de Controle Social e de Políticas Públicas, sindicatos, associações científicas, dentre estes, os relacionados com a área da saúde, educação, e outros (GRAU, 2006).

Reconhece-se que há críticas contundentes quanto à atuação desses setores da sociedade, dentre estas, destacam-se alguns contrapontos e/ou porque se transformaram em "partidos" ou porque funcionam como braço do Poder Executivo. Estes contrapontos revelam uma face obstruída da capacidade de decisão política e controle social destes órgãos, e são perceptíveis, mas não somente, em conselhos de acompanhamento e fiscalização de políticas sociais.

No campo da educação, estas práticas vêm sendo utilizadas desde a implantação do Sistema de Avaliação da Educação Básica (SAEB), quando em meados da década de 2000 foi criado um indicador sintético da educação, mais conhecido como Índice de Desenvolvimento da Educação Básica que prioriza os resultados de proficiência em língua portuguesa e matemática. Esses exames têm priorizado configurações da Nova Gestão Pública (NGP), discursando em defesa da melhoria dos resultados de aprendizagem, cujo foco principal é o desempenho do aluno em testes cognitivos. Ou seja, em certos pontos apropriação de formas de responsabilização, oriundas da NGP. Algumas descobertas revelam que estados e municípios têm utilizado este indicador como instrumento para construção de políticas e programas de responsabilidade educacional, cuja finalidade é premiação ou punição, de acordo com os resultados apresentados anualmente.

Ao considerar que também faz parte da sua finalidade a introdução de testes para avaliar a proficiência dos alunos, é preciso esclarecer, ao parafrasear Ravitch (2011) que "a testagem não é o problema", mas o uso equivocado da testagem para propósitos de grandes consequências e identificação de alunos que devem ser retidos e professores e diretores que devem ser demitidos ou recompensados. Essas práticas não conseguem tornar as organizações educativas mais iguais, fortalecendo as desigualdades. Nesse sentido, assume uma forma cruel de responsabilização que não condiz com uma concepção política de justiça social e democracia na escola. Os resultados das avaliações externas não conseguem revelar as qualidades das escolas, quando os instrumentos de avaliação e os avaliadores não consideram as condições objetivas de realização do trabalho pedagógico, tais como: infraestrutura, formação e valorização dos profissionais da educação, gestão democrática na forma de escolha de diretores e representantes eleitos para atuarem junto dos conselhos. Sabe-se que as eleições enquanto 
instrumento de voto e escolhas possuem suas limitações ${ }^{10}$, porém não podemos abrir mão disto, na condição de se ter mais um instrumento de fortalecimento dos processos de tomada de decisão na escola e ampliação da democracia.

\section{AVALIAÇÃO E RESPONSABILIZAÇÃO NO SISTEMA MUNICIPAL DE EDUCAÇÃO DE MOSSORÓ}

Mossoró-RN, o segundo maior município do Estado do Rio Grande do Norte, no final da primeira década dos anos 2000 implementou a política de responsabilidade educacional, aprovada por meio da lei 2.717/2010. Verifica-se, no corpo da lei que esta tem como objetivo em seu Art.1", a "melhoria da qualidade do sistema municipal de ensino, a partir da execução planejada, do estabelecimento de metas educacionais e investimento crescente e sistemático de recursos financeiros e da avaliação de desempenho" (MOSSORÓ-RN, 2011).

A preocupação desta lei de responsabilidade educacional (LRE) com o investimento crescente de recursos fica mais evidente em entrevista realizada por ocasião desta investigação, em que o entrevistado Anísio afirma:

(...) saímos com a ideia de elevar o índice de investimento da educação de $25 \%$ para $30 \%$ na cidade. Isso não era uma coisa fácil porque a cidade, ela, Mossoró como outras tantas, já fazia um esforço muito grande para completar os $25 \%$. Então já era um esforço grande para $25 \%$, como é que ia fazer $30 \%$. Mas eu participava das discussões.

De fato, a LRE estabelece a alocação crescente de recursos conforme Art. $6^{\circ}$, que para assegurar o cumprimento das metas de qualidade, sendo que o poder executivo municipal destinará alocação crescente dos recursos de receitas obedecendo ao seguinte cronograma: I $26 \%$ até o ano de 2011; II - 27\% até o ano de 2012; III - 28,5\% até o ano de 2013; IV - 30\% até o ano de 2014 (MOSSORÓ, 2011).

Portanto, a alocação crescente de recursos que estava no campo das ideias dos planejadores se materializou no texto da Lei 2.717/2010. Segundo o entrevistado, este aumento de recursos buscou se fundamentar no diagnóstico da Rede Municipal de Ensino e na construção do Planejamento Estratégico da Rede Municipal de Ensino, pois os dados eram preocupantes tais como:

${ }^{10}$ Cf. Paro (2003) 
Escolas com dificuldades, algumas escolas com péssimas condições de funcionamento, escolas precisando de reformas, outras precisando serem derrubadas mesmo, e reconstruídas e dentro daquelas condições de financiamento, você por mais que acredite, que defenda, inclusive como professor que sou, sei também da importância de investir na remuneração dos professores.

Considerando que a alocação crescente de recursos é uma conquista para a rede municipal de ensino, este princípio foi inserido também na perspectiva de ampliar o investimento na remuneração dos professores, conforme afirmou o entrevistado. Entretanto, a ideia de remuneração pode possuir dois sentidos que podem ser compostos por uma parte de salário permanente e outra variável (PASSONE, 2014). Não há na LRE a indicação de que a premiação financeira se tornará parte da remuneração fixa. Ressalta-se que os prêmios em forma de incentivos financeiros compõem historicamente as remunerações variáveis, acentuando um dos desafios da educação que é remunerar adequadamente os professores (PINTO, 2009).

A LRE afirma em seu Art. 10, que os indicadores e os resultados de cada uma das unidades educacionais deverão ser superiores, ao ano anterior. E ainda define no parágrafo único que serão apurados por ocasião da avaliação do Prêmio Escola de Qualidade, já instituído pelo município (MOSSORÓ-RN, 2011). Esta premiação é atribuída para os primeiros lugares que as escolas ocupam, e concorrem com escolas do seu porte (I, II, III ou IV). Nesse caso, professores, supervisores pedagógicos, e os demais funcionários receberão um prêmio de acordo com o parágrafo $6^{\circ}$, do Art. 11, em que corresponde "ao valor bruto da remuneração do servidor premiado, percebida no mês de novembro, não se incluindo nesse valor o adicional de férias e o décimo-terceiro salário". (MOSSORÓ-RN, 2011)

Nesse contexto, estabelece que dois alunos por escola também serão premiados, e segundo o parágrafo $7^{\circ}$, “O valor do prêmio de que trata este parágrafo será definido anualmente, por Decreto, depositado em caderneta de poupança, e deverá ser utilizado para a sua educação". Com isso, percebe-se a extensão de investimento de recursos no aluno, cuja ideia de aluno está vinculada com o sentido de ser aquele que tem as melhores notas das escolas, com a maior frequência em relação aos demais e a sua participação nos eventos escolares seja atestada pelos professores e demais profissionais da escola. 
Percebe-se que os incentivos financeiros estão atrelados a política de premiação do município, e que há uma forte relação desta logica com uma versão da responsabilização autoritária que consiste em definir prêmios restritos a um pequeno número de escolas e profissionais. No caso estudado a premiação financeira é vinculada ao Prêmio Escola de Qualidade, extensiva a todos os profissionais da escola, e a um dos alunos.

Para Anísio, o Prêmio Escola de Qualidade consiste em uma política ressignificada, que em sua origem não conseguia atingir diretamente o bolso do professor, por isso, buscou justificar a importância desta, com a ressalva de que era necessário incrementá-la com a bonificação financeira. A sua compreensão reflete acerca da necessidade de combinação entre avaliação e responsabilização:

Eu dizia que era uma ideia interessante, mas ela não era suficiente porque se você premia a escola, o professor que está dentro da escola ele não sente ainda o reflexo direto, imediato do esforço que ele fez. Então nós percebemos essa necessidade de que cada pessoa, cada elemento da escola sinta ele mesmo na vida dele, na remuneração dele, e para ser mais simplista no bolso dele o resultado do esforço que ele empreendeu.

Assim, verifica-se que o foco se concentrou na busca por resultados imediatos no trabalho do professor e o reconhecimento da sua responsabilidade individual ficam claros, deixando claro que as pessoas são reconhecidas de acordo com a sua produtividade (PASSONE, 2014). Sabe-se que estes elementos foram fabricados no âmbito da cultura da performatividade no campo educacional (BALL, 2001; 2004) em que o indivíduo é considerado de acordo com o que produz, e não consegue se dar conta que consistem na produção de uma crise dos valores. Alguns efeitos indesejados podem ocorrer, dentre eles a crise de valores éticos, a fragilidade nos relacionamentos educacionais e assim difundindo cada vez mais a máxima de que "os fins justificam os meios". Portanto, estas atitudes legitimam os efeitos "quase-mercantis" nas práticas educacionais. Por outro lado, emerge uma perspectiva de reconstruir uma nova ética que seja capaz de recuperar os laços afetivos e o rompimento com a competição desmedida entre os seres humanos.

\section{CONSIDERAÇÕES FINAIS}


No Brasil é possível reconhecer a presença de um Estado Avaliador, caracterizado principalmente pelo desenvolvimento expansivo das práticas de avaliações padronizadas ancoradas no pretenso objetivo de implementar a melhoria da qualidade da educação nos níveis aos quais estas avaliações se destinam.

Além da Prova Brasil e do IDEB, que compreendem uma política de responsabilização educacional em curso no país, corroborando para o fortalecimento de um Estado centrado em práticas de regulamentação da educação, com fins a um processo de "culpabilização" dos resultados produzidos pelas instituições de ensino, os municípios também têm construído mecanismos próprios de avaliação e regulação da educação local impulsionadas por esta "onda" do Estado Avaliador.

No caso do município de Mossoró/RN, desvela-se que a implantação de processos de avaliação por resultados, corroborando para ações competitivas entre as unidades educativas, instaurados pelo sistema de ensino local, tem contribuído para acentuar as desigualdades entre as escolas. Conclui-se que esta competição obstrui a capacidade política das escolas pertencentes a rede municipal de ensino, tolhendo o pensar sobre seu planejamento e inovar em suas ações cotidianas. Deste modo, estão sendo condicionadas a perseguir a racionalidade legal que estipula a conquista de um prêmio financeiro. A avaliação tem sido utilizada como meio de responsabilização pelo controle de resultados. Os impactos dos incentivos financeiros ainda precisam ser investigados na perspectiva de saber se o uso destes correspondem a uma melhoria da qualidade de ensino nas escolas.

Sendo assim, o pagamento do incentivo financeiro como forma de décimo quarto salário não alcança a todos do sistema, mas para uma minoria que já possuía uma organização nos moldes da política. Além disto, há outros meios que o sistema municipal utiliza para aumentar a sua eficiência, tais como: a premiação simbólica e financeira, e alocação crescente de recursos, Sistema de Avaliação da Educação Municipal-SAEM. Alerta-se para que a gestão educacional no contexto da avaliação por incentivos financeiros não se configure como instrumentos de obstrução da capacidade política do sistema (OFFE, 1984).

Portanto, a experiência do município de Mossoró-RN contribui para uma reflexão profunda acerca da implantação de um processo de accountability, até certo ponto mais próximo de uma perspectiva congruente, porém com dificuldades para incorporar elementos de autonomia e participação, ou seja, valores democráticos. Finalmente, os desdobramentos da 


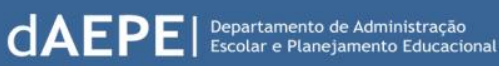

\section{ISSN 2359-82}

política de responsabilidade educacional revelam fragilidades nos processos de avaliação e responsabilização, enquanto interlocutora de prestação de contas.

\section{REFERÊNCIAS}

ANASTASIA, Fátima. Responsabilização pelos controles clássicos. In: BRESSER-PEREIRA, Luiz C.; GRAU, Nuria Cunnil (coord.). Responsabilização na Administração Pública. São Paulo: CLAD/FUNDAP, 2006, p. 71-112.

ABRUCIO, Fernando Luiz. Responsabilização pela competição administrada. BRESSERPEREIRA, Luiz C.; GRAU, Nuria Cunnil (coord.). Responsabilização na Administração Pública. São Paulo: CLAD/FUNDAP, 2006, p. 217-262.

ARENDT, Hannah. Responsabilidade e julgamento. Tradução Rosaura Eichenberg. São Paulo: Companhia das Letras, 2004.

BALL, Stephen. Diretrizes Políticas Globais e Relações Políticas Locais em Educação. Currículos sem fronteiras, 2, 99-116, 2001.

BRESSER-PEREIRA, Luiz Carlos. Apresentação da edição brasileira: as formas de responsabilização na gestão pública. In: Bresser-Pereira, Luiz C. \& Grau, Nuria Cunnil (coord.). Responsabilização na Administração Pública. São Paulo: CLAD/FUNDAP, 2006, p. 7.

BRASIL. Constituição Federal de 1988. Promulgada em 05 de outubro de 1988. Disponível em: http://www.planalto.gov.br/ccivil_03/constituicao/ConstituicaoCompilado.htm

Lei n. 10.172, de 09 de janeiro de 2001. Aprova o Plano Nacional de Educação (PNE). Diário Oficial da União [da] República Federativa do Brasil, Brasília, DF, 10 jan. 2001.

FREITAS, Luiz Carlos. Avaliação educacional: caminhando pela contramão. 3.ed. Petrópolis, RJ: Vozes, 2011.

FREITAS, Luiz Carlos. Os Reformadores Empresariais da Educação: de desmoralização do magistério à destruição do sistema público de educação. Educação \& Sociedade, Campinas, v. 33, n, 119, p. 376-404, 2012. 
GRAU, Nuria Cunnil. Responsabilização pelo controle social. BRESSER-PEREIRA, Luiz C.; GRAU, Nuria Cunnil (coord.). Responsabilização na Administração Pública. São Paulo: CLAD/FUNDAP, 2006. pp. 263-322,

GRUENING, Gernod. Origin and theoretical basis of New Public Management. International Public Management Journal, 4, 1-25, (2001).

HOOD, Cristopher. The "new public management" in the 1980s: variations on a theme. Accounting, Organizations e Society, v. 20, 93-109, 1995.

HARVEY, David. O enigma do capital e as crises do capitalismo. Tradução de João Alexandre Peschanski. São Paulo: Boitempo Editorial, 2011a.

HARVEY, David. O neoliberalismo: história e implicações. São Paulo: Edições Loyola, 2011 b.

MOSSORÓ. Lei $\mathrm{n}^{\mathrm{o}} 2.717$, de 27 de dezembro de 2010. Lei complementar $\mathrm{n}^{\mathrm{o}} 048$ de 16 de dezembro de 2010. Institui a política de Responsabilidade Educacional no município de Mossoró e dá outras providências. Jornal Oficial de Mossoró, Mossoró-RN, Ano IV, n. 75ª terça-feira, 04 de janeiro de 2011.

OFFE, Claus. Problemas estruturais do Estado capitalista. Rio de Janeiro: Ed. Tempo Brasileiro, 1984.

PARO, Vitor H. Eleição de diretores: a escola pública experimenta a democracia. 2. ed. São Paulo: Xamã, 2003.

PASSONE, Eric. Incentivos monetários para professores: avaliação, gestão e responsabilização na educação. Cadernos de Pesquisa, n. 152, p. 424-448, abr./jun. 2014.

PINTO, José M. R. Remuneração adequada do professor: desafio à educação brasileira. Retratos da Escola, Brasília, v. 3, n. 4, p. 51-67, jan./jun. 2009. Disponível em: http://www.esforce.org.br/index.php/semestral/article/viewFile/101/290

QUIRÓS, Mario M. Responsabilização pelo controle de resultados. Bresser-Pereira, Luiz C. \& Grau, Nuria Cunnil (coord.). Responsabilização na Administração Pública. São Paulo: CLAD/FUNDAP, p. 165-216, 2006. 
RAVITCH, Diane. Vida e Morte do Grande Sistema Escolar Americano: como os testes padronizados e o modelo de mercado ameaçam a educação. Porto Alegre: Sulina, 2011.

SCHINEIDER, Marilda P.; ROSTIROLA, Camila R. Estado-Avaliador: reflexões sobre sua evolução no Brasil. Revista Brasileira de Política e Administração da Educação, v. 31, n. 3, p. 493-510, 2015.

XIMENES, Salomão B. Responsabilidade educacional: concepções diferentes e riscos iminentes ao direito à educação. Revista Educação e Sociedade, v. 33, n.119, 353-377, 2012. Disponível em: http://www.scielo.br/pdf/es/v33n119/a03v33n119.pdf Acesso em: 23/03/2016.

ZIZEK, Slavoj. Problema no Paraíso: do fim da história ao fim do capitalismo. São Paulo: Zahar, 2015. 